\title{
Effects of Intermittent Low Temperature Storage Duration and Cycle on the Growth and Flowering of Eustoma (Eustoma grandiflorum L.) Seedlings Raised in the Summer
}

\author{
Thao Thu Phan', Satoshi Sasaki', Keigo Fukushima², Yoshiyuki Tanaka ${ }^{1,3}$, \\ Ken-ichiro Yasuba ${ }^{1}$, Yuichi Yoshida ${ }^{1}$ and Tanjuro Goto ${ }^{1 *}$ \\ ${ }^{1}$ Graduate School of Environmental and Life Science, Okayama University, Okayama 700-8530, Japan \\ ${ }^{2}$ Hiroshima Prefectural Technology Research Institute, Agricultural Technology Research Center, Higashihiroshima 739-0151, \\ Japan \\ ${ }^{3}$ Graduate School of Agriculture, Kyoto University, Kyoto 606-8502, Japan
}

In the present study, we evaluated the effects of intermittent low temperature storage (ILTS) following cold imbibition of Eustoma seeds as a low-cost method. The objective of this study was to investigate the effects of the total number of cold storage days and the lengths of ILTS cycles for seedlings on the subsequent growth and flowering of three cultivars with different susceptibilities to rosetting: 'Nancy', 'Exe Lavender', and 'Bolero White'. Before sowing, the seeds were imbibed with water at $10^{\circ} \mathrm{C}$ under a dark condition for 35 days. A cycle of $6 \mathrm{D} / 6 \mathrm{D}\left(6\right.$ days in a refrigerator kept at $10^{\circ} \mathrm{C}$ in the dark $/ 6$ days in a greenhouse kept at a high ambient temperature) was repeated $0,1,2,3,4$, and 5 times to attain $0,6,12,18,24$, and 30 days of cold storage (DCS), respectively. Using a cycle of $6 \mathrm{D} / 6 \mathrm{D}$ at least one time (6 DCS) increased the bolting and flowering percentages and accelerated the bolting date by 6-10 days and the flowering date by 4-9 days in 'Nancy', a high-rosetting cultivar. The percentage of harvesting was above $80 \%$ only in seedlings subjected to 24 and 30 DCS in ILTS. In addition, under equal 30 DCS of ILTS, cycles of 3D/3D $\times 10$ times, $6 \mathrm{D} / 6 \mathrm{D} \times 5$ times, and $15 \mathrm{D} / 15 \mathrm{D} \times 2$ times were investigated by exposing the seedlings to a high ambient temperature for 3,6 , and 15 days and then transferring them to a refrigerator $\left(10^{\circ} \mathrm{C}\right)$ for 3,6 , and 15 days, respectively. ILTS cycles of 3D/3D and 6D/6D resulted in earlier bolting and flowering dates than cycles of 15D/15D. The cycle of 15D/15D resulted in a lower percentage of marketable harvesting and an increased number of nodes to the first flower. These results suggest that applying ILTS with a cycle of 6D/6D at least four times can be an efficient method to promote the bolting and flowering of Eustoma without applying air conditioning to the entire greenhouse.

Key Words: bolting, cold storage, cut flower quality, high ambient temperature, rosette.

\section{Introduction}

Eustoma (Eustoma grandiflorum L.) is widely grown for the production of potted flowers and cut flowers throughout the world. In Japan, the demand for Eustoma cut flowers is especially high during the New Year holidays. In order to produce cut flowers for this season, the plants need to be sown in late July to early August and transplanted in early September. In

Received; September 25, 2019. Accepted; December 24, 2019.

First Published Online in J-STAGE on March 10, 2020.

Part of this study was presented at the 2014 Spring Meeting of the Japanese Society for Horticultural Science.

* Corresponding author (E-mail: tangoto@okayama-u.ac.jp).
Eustoma, rosetting easily occurs in young seedlings following exposure to high temperatures (Harbaugh et al., 1992; Li et al., 2002; Ohkawa et al., 1991). To prevent rosetting, cold imbibition of Eustoma seeds has been widely used recently (Fukushima et al., 2017; Kageyama et al., 1990; Tanigawa et al., 1999).

Although imbibing seeds under low temperatures has become a very common practice, increasing summer temperatures caused by global warming is unfavorable for the growth of seedlings of various high-rosetting Eustoma cultivars in southwestern Japan. For this reason, even during the cultivation of cold-imbibed seeds, it is necessary to cool the temperatures of greenhouses $\left(25^{\circ} \mathrm{C} / 15^{\circ} \mathrm{C}\right.$, day/night) using air conditioners in the summer to harvest qualified cut flowers up to the end of 
the year. However, the installation and energy consumption to maintain air conditioning systems throughout the period of seedlings growth require are expensive. Therefore, the development of alternative cost-effective procedures to ensure stable flowering and good seedling growth is needed.

Recently, intermittent low temperature storage (ILTS), in which plants are repeatedly transferred between a refrigerator (low temperature) and ambient conditions (high temperature), was reported as a useful and low-cost procedure for flower induction of Junebearing strawberries (Yoshida et al., 2012). In this study, it was found that in plants subjected to ILTS, the flowering was earlier and more uniform compared to strawberry plants grown under a continuous dark cold storage condition. The supply of assimilates due to outdoor photosynthesis during ILTS may be an important factor. Furthermore, the flowering of potted plants was found to be accelerated by applying ILTS in Begonia $\times$ hiemalis 'Netja' (Nakajima and Goto, 2018). During ILTS in these plants, effects of the application of low temperatures, high temperature avoidance, and shortday have been reported (Nakajima and Goto, 2018; Yoshida et al., 2012). In Eustoma, previous studies reported that the plants need a low temperature environment after sowing or planting to enhance the rate of stem elongation and bolting speed (Pergola, 1992; Takeda, 1995). With the aim of producing good quality seedlings in the summer and producing cut flowers for the end of the year, ILTS could be an efficient method for growing cold-imbibed Eustoma seeds. However, application of ILTS has not yet been examined in Eustoma. In the present study, we investigated the effects of the total number of cold storage days and the lengths of ILTS cycles during the growing period of Eustoma seedlings on the subsequent bolting and flowering of cultivars with different susceptibilities to rosetting.

\section{Materials and Methods}

\section{General}

ILTS was conducted from sowing (July) to transplanting (September). Eustoma seeds were imbibed with distilled water at $10^{\circ} \mathrm{C}$ under a dark condition for 35 days and then sown in cell trays (288-cell size) before beginning the ILTS procedure. ILTS was performed with a $\mathrm{xD} / \mathrm{xD}$ cycle $\times$ repeated time in which the seedlings were rotationally transported between a refrigerator $\left(10^{\circ} \mathrm{C}\right)$ and a greenhouse at an ambient temperature of a set number of days (x days). The cycle was repeated several times to complete the total number of cold storage days for each experiment (Fig. 1). Dur-
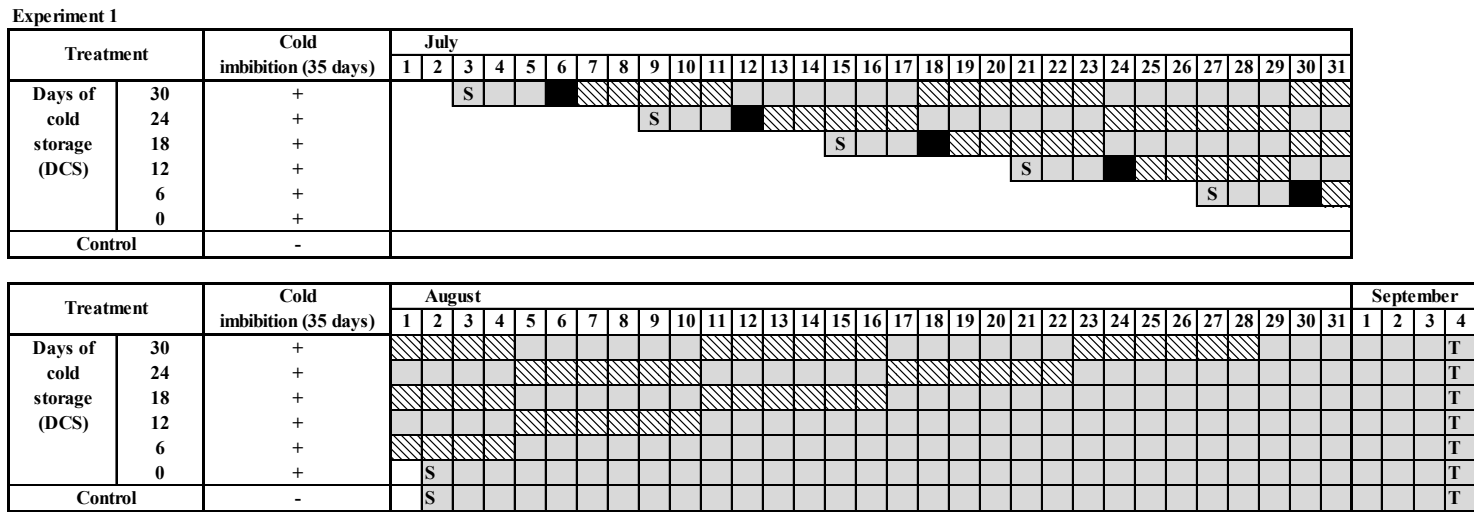

Experiment 2

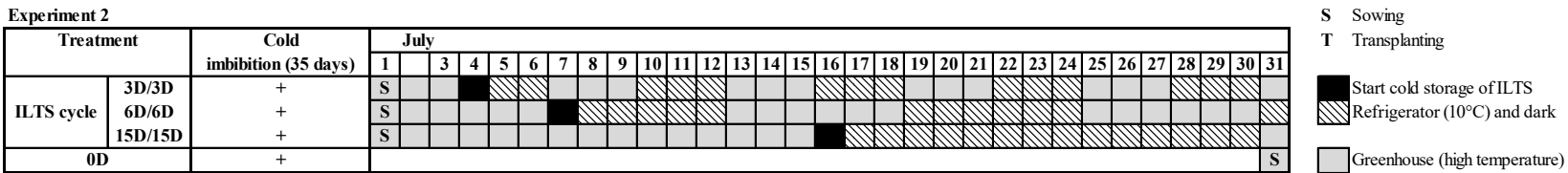

\begin{tabular}{|c|c|c|c|c|c|c|c|c|c|c|c|c|c|c|c|c|c|c|c|c|c|c|c|c|c|c|c|c|c|c|c|c|c|c|c|}
\hline \multirow{2}{*}{\multicolumn{2}{|c|}{ Treatment }} & \multirow{2}{*}{$\begin{array}{c}\text { Cold } \\
\text { imbibition (35 days) } \\
\end{array}$} & \multicolumn{29}{|c|}{ August } & \multicolumn{4}{|c|}{ September } \\
\hline & & & 1 & 2 & 3 & 4 & 5 & 6 & 7 & 8 & 9 & 10 & 11 & 12 & 13 & \begin{tabular}{l|l}
14 & 1 \\
\end{tabular} & \begin{tabular}{l|l|}
15 & 1 \\
\end{tabular} & \begin{tabular}{l|l|}
6 & 17 \\
\end{tabular} & 18 & 19 & \begin{tabular}{|l|l|}
20 & 2 \\
\end{tabular} & \begin{tabular}{l|l|}
21 & 22 \\
\end{tabular} & \begin{tabular}{l|l|}
22 & 23 \\
\end{tabular} & \begin{tabular}{|l|l|}
3 & 24 \\
\end{tabular} & 25 & 26 & $27 \mid$ & & 29 & 30 & 31 & 1 & 2 & 3 & 4 \\
\hline \multirow{3}{*}{ ILTS cycle } & 3D/3D & + & & & & & & & & & & & & & & & & & & & & & & & & & & & & & & & $\mathbf{T}$ & & \\
\hline & 6D/6D & + & & & & & & & & & & & & & & & & & & & & & & & & & & & & & & & $T$ & & \\
\hline & 15D/15D & + & & & & & & & & & & & & & & & & & & & & & & & & & & & & & & & $\mathbf{T}$ & & \\
\hline \multicolumn{2}{|c|}{ OD } & + & & & & & & & & & & & & & & & & & & & & & & & & . & & & & & & & $T$ & & \\
\hline
\end{tabular}

Fig. 1. Scheme of intermittent low temperature storage (ILTS) treatments. All Eustoma seeds were treated by cold imbibition in the dark for 35 days before being subjected to ILTS. In experiment 1, an ILTS cycle of $6 \mathrm{D} / 6 \mathrm{D}$ was started three days after sowing. Seedlings were placed in a refrigerator $\left(10^{\circ} \mathrm{C}\right)$ for six days and then transferred to a greenhouse (high temperature) for six days. This cycle was repeated $5,4,3,2,1$, and 0 times to attain 30,24, 18,12, 6, and 0 days of cold storage (DCS). Seeds subjected to cold imbibition, but not ILTS, were used as a control. In experiment 2, ILTS cycles of 3D/3D $\times 10$ times, $6 \mathrm{D} / 6 \mathrm{D} \times 5$ times, and $15 \mathrm{D} / 15 \mathrm{D} \times 2$ times were investigated. Seedlings were placed in a greenhouse at an ambient temperature for 3,6, and 15 days, and then transferred to a refrigerator for 3,6 , and 15 days, respectively. Seeds of $0 \mathrm{D}$ were cold-imbibed before sowing, but not subjected to ILTS. The total numbers of days of low- and high-temperature exposures were the same at 30 days and 33 days among all ILTS treatments. 
ing the treatment time in the greenhouse (ambient day length and high ambient temperature), seeds were placed under mist irrigation to germinate until the cotyledons expanded completely. Then, the seedlings were supplied daily with OAT A solution $(\mathrm{N}, 17.7 \mathrm{mM}$; $\mathrm{P}, 1.7 \mathrm{mM} ; \mathrm{K}, 7.8 \mathrm{mM}$; Ca, $4.2 \mathrm{mM} ; \mathrm{Mg}, 1.86 \mathrm{mM}$; OAT Agrio Co., Ltd., Japan) at 1/6 strength and by subirrigation until transplanting while in the greenhouse. When moved to a refrigerator, the seedlings were stored at $10^{\circ} \mathrm{C}$ without lighting or irrigation. When ILTS was completed, six seedlings were transplanted to a planter $(64 \mathrm{~cm} \times 22 \mathrm{~cm} \times 18 \mathrm{~cm}$, soil capacity $15.0 \mathrm{~L})$ as one replication and there were three replications per treatment. The planters of transplanted seedlings were placed in a greenhouse kept at $15^{\circ} \mathrm{C}$ minimum for $16 \mathrm{~h}$ of day length (natural day length with additional lighting by an incandescent lamp from 4:00 to 9:00 and from 16:00 to 20:00). Ten days after transplanting, 1.5 liters of $1 / 2$ strength OAT A solution was applied to each planter once a week. The air temperature in the greenhouse was recorded every 5 min using a datalogger (Ondotori TR-71Ui; T\&D Corporation, Japan).

The bolting date and bolting node were recorded when the length of an internode exceeded $5 \mathrm{~mm}$. Rosetting was determined when the plant did not bolt 60 days after transplanting. The dates of flowering (when the first flower opened) was recorded for all plants except the rosetted ones. Flowering shoots were harvested when the fourth flower opened and cut flower traits were investigated such as fresh weight and length, the number of nodes to the first flower, and the total numbers of visible flower buds and flowers. Cut flowers with more than a total of six flowers including flower buds were used to calculate the marketable harvesting percentage. The mean values of each replication were subjected to one-way ANOVA and means were compared using Tukey's HSD test (Excel-toukei 2010; Social Survey Research Information Co., Ltd., Japan).

Experiment 1. Effect of total duration of low temperature storage applied intermittently

In this experiment, a mild-rosetting cultivar, 'Exe Lavender' (Kaneko Seeds Co., Ltd., Japan), and a highrosetting cultivar, 'Nancy' (Fukukaen Nursery \& Bulb Co., Ltd., Japan), were examined in 2018. In our preliminary experiments, the rate of rosetting was $44.4 \%$ in 'Exe Lavender' and $92.9 \%$ in 'Nancy' under a natural high temperature season (unpublished data). After the end of cold imbibition, seeds of both cultivars were sown and placed in a greenhouse for three days. After that, the seeds were placed in a refrigerator for six days, and then moved to a greenhouse for six days (cycle of $6 \mathrm{D} / 6 \mathrm{D})$. The cycle of $6 \mathrm{D} / 6 \mathrm{D}$ was repeated $0,1,2,3,4$, and 5 times to attain $0,6,12,18,24$, and 30 days of cold storage (DCS), respectively. The Eustoma coldimbibed seeds were sown in 2018 on July 3, 9, 15, 21, 27, and August 2 depending on the duration of low tem- perature storage (Fig. 1). The duration of high ambient temperature exposure was the same for all the treatments at 33 days. Seeds of the control (without any low temperature treatment) were also examined and sown on August 2. All seedlings were transplanted on September 4 .

\section{Experiment 2. Effect of intermittent low temperature storage cycles}

A low-rosetting cultivar 'Bolero White' (Miyoshi Co. Ltd., Japan) and the high-rosetting cultivar 'Nancy' were examined. In the preliminary experiment, the rate of rosetting was $7.1 \%$ in 'Bolero White' under a natural high temperature season (unpublished data). Before ILTS, the seeds of both cultivars were imbibed in water at $10^{\circ} \mathrm{C}$ on May 27, 2013, until sowing. After sowing, the seeds were placed in a greenhouse for 3,6 , and 15 days and then placed in a refrigerator for 3,6 , and 15 days, respectively. ILTS cycles $\times$ repeated time of $3 \mathrm{D} / 3 \mathrm{D} \times 10$ times, $6 \mathrm{D} / 6 \mathrm{D} \times 5$ times, and $15 \mathrm{D} / 15 \mathrm{D} \times 2$ times were investigated (Fig. 1). The total exposure to low temperature and high-temperature conditions were designed to be the same in all treatments of 30 days and 33 days, respectively. 0D seeds were imbibed at $10^{\circ} \mathrm{C}$ on June 26, 2013, and sown on July 31, but not subjected to ILTS. All seedlings were transplanted on September 2 .

\section{Results}

Experiment 1. Effect of total duration of low temperature storage applied intermittently

During the seedling growth in 2018 (JulySeptember), the daily mean temperature ranged from $24.3^{\circ} \mathrm{C}$ to $34.1^{\circ} \mathrm{C}$; it was mostly higher than $30^{\circ} \mathrm{C}$ in the period July 13-August 14 (except for August 7-8) and August $21-30$. The average daily minimum temperature, daily mean temperature, and daily maximum temperature were $25.0^{\circ} \mathrm{C}, 30.7^{\circ} \mathrm{C}$, and $38.3^{\circ} \mathrm{C}$, respectively (Fig. 2).

Treatments with ILTS that started three days after

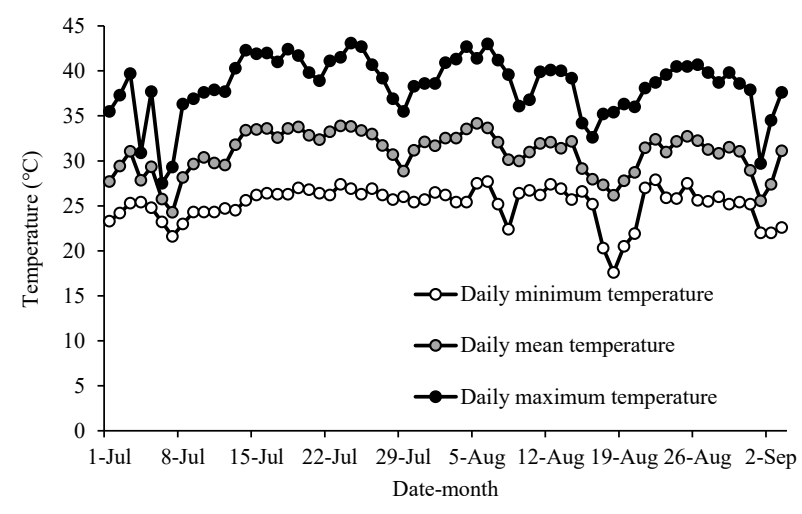

Fig. 2. Daily mean and daily maximum and minimum temperatures recorded during the 2018 growing period from July 1 to September 4. 
sowing the cold-imbibed seeds, accelerated bolting by 3-7 days in 'Exe Lavender' and by 6-10 days in 'Nancy' compared to no ILTS treatment (0 DCS) (Table 1). In a mild-rosetting cultivar, 'Exe Lavender', $88.9 \%$ of control plants started rosetting whereas most of cold treatment plants resulted in bolting. Although there was no significant difference in the bolting date or flowering date, ILTS treatments only affected the flowering percentage. No ILTS treatment using only cold imbibition of seeds (0 DCS) improved the induction rate to $94.4 \%$ bolting, but induced only $50.0 \%$ of the total plants to flower by December 20 (Table 1). Most ILTS treatments resulted in $100 \%$ bolting (excepted for the 12 DCS treatment) and over $70 \%$ flowering. Twenty-four and 30 DCS resulted in a significantly higher percentage of flowering compared with 0,6 , and 12 DCS (Table 1). Moreover, plants grown in 24 and 30 DCS started to flower and reached a half of the total flowering rate earlier than those grown using shorter lengths of cold storage (Fig. 3). In the high-rosetting cultivar, 'Nancy', all control plants formed rosettes. Although the 0 DCS treatment and other durations of ILTS induced $94.4 \%$ and $100 \%$ bolting, respectively, the bolting date of the 0 DCS treatment was 7-10 days later than that of plants treated more than 12 days (Table 1). The percentage of flowering was greatest and the number of days to flowering was lowest in 24 DCS and 30 DCS (Table 1). Plants grown in 24 and 30 DCS achieved $83 \%$ flowering on December 7 , while those grown in 6,12 , and 18 DCS showed a flowering rate lower than $60 \%$ on the same day (Fig. 4); however, there was no significant difference in flowering in the 12-30 DCS treatments.

The duration of low temperature storage affected the percentage of harvesting until December 31 in both 'Exe Lavender' and 'Nancy' (Table 2). By increasing the low temperature days to 30 days, the percentage of harvesting increased markedly to over $80 \%$. However, there was no significant difference in cut flower length, number of flowers or visible flower buds in treatments for 'Exe Lavender'. The number of nodes to the first flower was largest in the 0 DCS treatment (10.3). In 'Nancy', the highest percentage of harvesting and the longest cut flower length were both with 30 DCS. There

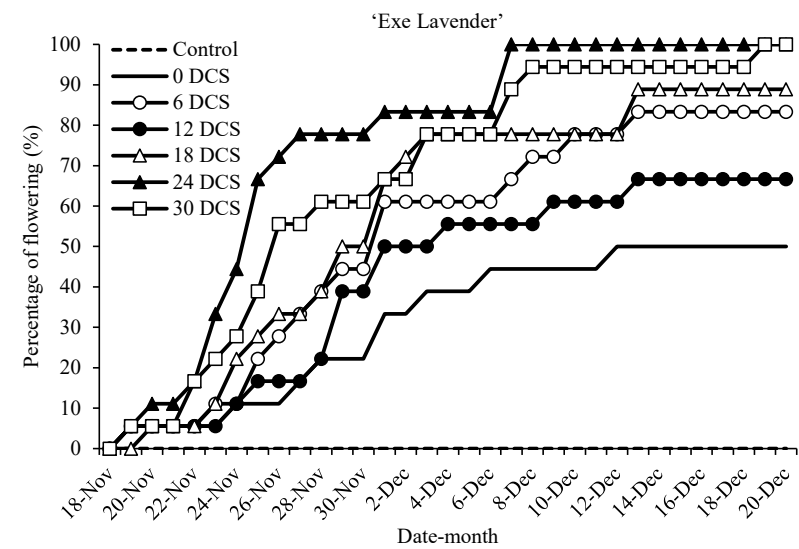

Fig. 3. Percentage of flowering of 'Exe Lavender' recorded at different numbers of cold storage days every day until December 20 .

Table 1. Effect of the day of cold storage (DCS) on the bolting date, bolting nodes, and percentage of bolting at 60 days after transplanting in 2018. The flowering date and percentage of flowering were recorded up to December 20. After the end of cold imbibition, Eustoma seeds were sown in cell trays and subjected to ILTS. Cold duration is the total number of days that cell trays were placed in a refrigerator $\left(10^{\circ} \mathrm{C}\right)$ during ILTS. An ILTS cycle of $6 \mathrm{D} / 6 \mathrm{D}$ was used in this experiment (see more details in Figure 1).

\begin{tabular}{|c|c|c|c|c|c|c|}
\hline Cultivar & $\begin{array}{l}\text { Day of cold storage } \\
\text { (DCS) }\end{array}$ & Bolting date & Bolting node & $\begin{array}{c}\text { Percentage of bolting } \\
(\%)\end{array}$ & Flowering date & $\begin{array}{l}\text { Percentage of } \\
\text { flowering (\%) }\end{array}$ \\
\hline \multirow[t]{7}{*}{ 'Exe Lavender' } & Control & $17-O c t b^{z}$ & 9.0 & $11.1 \mathrm{~b}^{\mathrm{y}}$ & $-^{x}$ & $0.0 \mathrm{~d}$ \\
\hline & 0 & 28-Sep a & 4.0 & $94.4 \mathrm{a}$ & 30-Nov a & $50.0 \mathrm{c}$ \\
\hline & 6 & 25-Sep a & 3.8 & $100.0 \mathrm{a}$ & 30-Nov a & $83.3 \mathrm{bc}$ \\
\hline & 12 & 25-Sep a & 4.0 & 88.9 a & 1-Dec a & $72.2 \mathrm{bc}$ \\
\hline & 18 & 23-Sep a & 3.8 & $100.0 \mathrm{a}$ & 29-Nov a & $88.9 \mathrm{abc}$ \\
\hline & 24 & 21-Sep a & 3.7 & $100.0 \mathrm{a}$ & 26-Nov a & $100.0 \mathrm{a}$ \\
\hline & 30 & 23-Sep a & 3.5 & $100.0 \mathrm{a}$ & 28-Nov a & $100.0 \mathrm{a}$ \\
\hline \multirow[t]{7}{*}{ 'Nancy' } & Control & - & - & $0.0 \mathrm{~b}$ & - & $0.0 \mathrm{c}$ \\
\hline & 0 & 27-Sep b & 3.6 & $94.4 \mathrm{a}$ & 10-Dec a & $44.4 \mathrm{bc}$ \\
\hline & 6 & 21-Sep ab & 3.2 & $100.0 \mathrm{a}$ & 6-Dec a & $72.2 \mathrm{abc}$ \\
\hline & 12 & 20-Sep a & 3.2 & $100.0 \mathrm{a}$ & 6-Dec a & $66.7 \mathrm{abc}$ \\
\hline & 18 & 20-Sep a & 3.1 & $100.0 \mathrm{a}$ & 4-Dec a & $83.3 \mathrm{ab}$ \\
\hline & 24 & 17-Sep a & 3.0 & $100.0 \mathrm{a}$ & 1-Dec a & $100.0 \mathrm{a}$ \\
\hline & 30 & 19-Sep a & 3.0 & $100.0 \mathrm{a}$ & 3-Dec a & $100.0 \mathrm{a}$ \\
\hline
\end{tabular}

\footnotetext{
${ }^{z}$ Mean values $(\mathrm{n}=3)$ followed by different letters indicate significant differences among different cold durations of ILTS $(P<0.05$, Tukey's HSD test).

y Percentage values were transformed to arcsin values.

${ }^{x}$ There was no data.
} 
was no significant difference in the number of nodes to the first flower, cut flower weight, or number of flowers and visible flower buds among ILTS treatments of this cultivar.

\section{Experiment 2. Effects of intermittent low temperature} storage cycles

During the seedling growth in 2013 (JulySeptember), the daily mean temperature ranged from $20.1^{\circ} \mathrm{C}$ to $32.1^{\circ} \mathrm{C}$; it was mostly higher than $25^{\circ} \mathrm{C}$ and decreased to $23^{\circ} \mathrm{C}$ in early September. The average daily minimum temperature, daily mean temperature and daily maximum temperature were $24.3^{\circ} \mathrm{C}, 28.9^{\circ} \mathrm{C}$, and $35.5^{\circ} \mathrm{C}$, respectively (Fig. 5).

In a low-rosetting cultivar, 'Bolero White', 100\% bolting and flowering were achieved in all treatments, but the bolting date and flowering date for ILTS cycles of $3 \mathrm{D} / 3 \mathrm{D}$ and $6 \mathrm{D} / 6 \mathrm{D}$ were earlier than those of $0 \mathrm{D}$ and 15D/15D (Table 3). In the high-rosetting cultivar

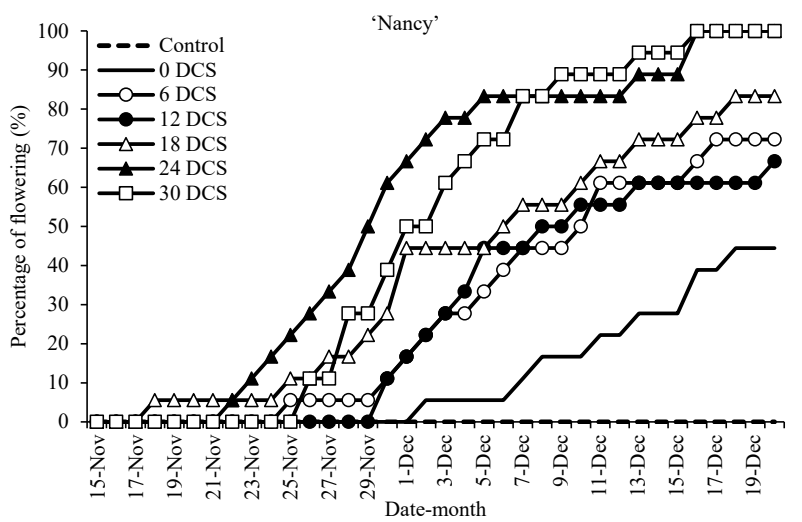

Fig. 4. Percentage of flowering of 'Nancy' recorded at different numbers of cold storage days every day until December 20.
'Nancy', $100 \%$ bolting was also observed in all treatments and $100 \%$ flowering was observed in all plants treated with ILTS, whereas plants grown without ILTS resulted in only $66.7 \%$ flowering (Table 3; Fig. 6). Seedlings grown under ILTS cycles of $6 \mathrm{D} / 6 \mathrm{D}$ and $3 \mathrm{D} / 3 \mathrm{D}$ generally bolted and produced flowers in a similar manner. Their bolting and flowering were earlier than those of the 0D treatment by 11 days and 23-25 days, respectively. Flowering in $15 \mathrm{D} / 15 \mathrm{D}$ was delayed by $13-14$ days compared with $6 \mathrm{D} / 6 \mathrm{D}$ and $3 \mathrm{D} / 3 \mathrm{D}$ (Table 3; Fig. 6).

Table 4 shows the effects of ILTS cycles on cut flower traits of 'Nancy' up to December 31. Only $62.5 \%$ of seedlings without ILTS produced cut flowers, whereas all seedlings treated with ILTS produced cut flowers up to December 31 . However, only the cycle of $6 \mathrm{D} / 6 \mathrm{D}$ achieved $100 \%$ marketable harvesting. There was no

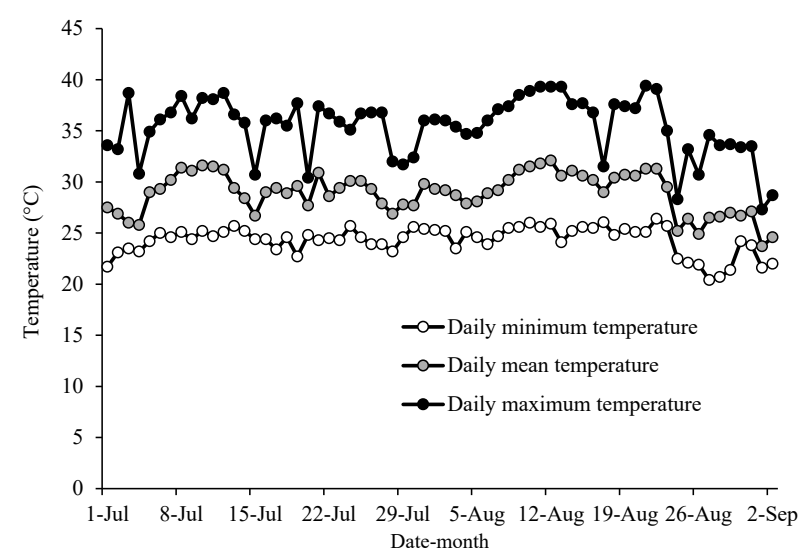

Fig. 5. Daily mean and daily maximum and minimum temperatures recorded during the 2013 growing period from July 1 to September 2 .

Table 2. Effect of cold duration (days) of ILTS on the harvesting date, percentage of harvesting, and cut flower characteristics up to December 31 in 2018 .

\begin{tabular}{|c|c|c|c|c|c|c|c|}
\hline Cultivar & $\begin{array}{c}\text { Day of cold } \\
\text { storage (DCS) }\end{array}$ & Harvesting date & $\begin{array}{r}\text { Percentage of } \\
\text { harvesting (\%) }\end{array}$ & $\begin{array}{l}\text { Cut flower } \\
\text { length }(\mathrm{cm})\end{array}$ & $\begin{array}{l}\text { Cut flower } \\
\text { weight }(\mathrm{g})\end{array}$ & $\begin{array}{l}\text { Number of nodes } \\
\text { to the first flower }\end{array}$ & $\begin{array}{l}\text { Number of } \\
\text { flowers and } \\
\text { visible buds }\end{array}$ \\
\hline \multirow[t]{6}{*}{ 'Exe Lavender' } & 0 & $18-$ Dec a $^{\mathrm{z}}$ & $22.2 b^{y}$ & $43.5 \mathrm{a}$ & $45.7 \mathrm{a}$ & $10.3 \mathrm{~b}$ & $4.0 \mathrm{a}$ \\
\hline & 6 & 17-Dec a & $44.4 \mathrm{ab}$ & $38.1 \mathrm{a}$ & $43.4 \mathrm{ab}$ & $9.2 \mathrm{a}$ & $4.3 \mathrm{a}$ \\
\hline & 12 & 19-Dec a & $27.8 \mathrm{~b}$ & $37.2 \mathrm{a}$ & $42.3 \mathrm{ab}$ & $9.2 \mathrm{a}$ & $2.7 \mathrm{a}$ \\
\hline & 18 & 18-Dec a & $27.8 \mathrm{~b}$ & $43.0 \mathrm{a}$ & $46.5 \mathrm{a}$ & $9.0 \mathrm{a}$ & $4.3 \mathrm{a}$ \\
\hline & 24 & 15-Dec a & $72.2 \mathrm{ab}$ & $41.2 \mathrm{a}$ & $43.7 \mathrm{ab}$ & $9.0 \mathrm{a}$ & $4.1 \mathrm{a}$ \\
\hline & 30 & 22-Dec a & $83.3 \mathrm{a}$ & $38.8 \mathrm{a}$ & $35.1 \mathrm{~b}$ & $9.2 \mathrm{a}$ & $3.1 \mathrm{a}$ \\
\hline \multirow[t]{6}{*}{ 'Nancy' } & 0 & 23-Dec b & $22.2 \mathrm{c}$ & $56.5 \mathrm{ab}$ & $52.2 \mathrm{a}$ & $10.7 \mathrm{a}$ & $7.5 \mathrm{a}$ \\
\hline & 6 & 21-Dec ab & $66.1 \mathrm{bc}$ & $54.0 \mathrm{ab}$ & $49.6 \mathrm{a}$ & $10.4 \mathrm{a}$ & $6.7 \mathrm{a}$ \\
\hline & 12 & 17-Dec ab & $50.0 \mathrm{bc}$ & $51.8 \mathrm{~b}$ & $53.9 \mathrm{a}$ & $10.4 \mathrm{a}$ & $7.3 \mathrm{a}$ \\
\hline & 18 & 11-Dec a & $50.0 \mathrm{bc}$ & $51.6 \mathrm{~b}$ & $57.1 \mathrm{a}$ & $10.8 \mathrm{a}$ & $7.8 \mathrm{a}$ \\
\hline & 24 & 15-Dec ab & $88.9 \mathrm{ab}$ & $62.6 \mathrm{ab}$ & $52.1 \mathrm{a}$ & $10.2 \mathrm{a}$ & $7.6 \mathrm{a}$ \\
\hline & 30 & 16-Dec ab & $100.0 \mathrm{a}$ & $67.1 \mathrm{a}$ & $56.1 \mathrm{a}$ & $10.3 \mathrm{a}$ & $8.4 \mathrm{a}$ \\
\hline
\end{tabular}

${ }^{z}$ Mean values $(n=3)$ followed by different letters indicate significant differences among different cold durations of ILTS $(P<0.05$, Tukey's HSD test).

y Percentage values were transformed to arcsin values. 
Table 3. Effect of ILTS cycles on the bolting date and percentage of bolting more than 60 days after transplanting. The date and percentage of flowering are up to December 21 in 2013. Details of treatments are presented in Figure 1.

\begin{tabular}{|c|c|c|c|c|c|}
\hline Cultivar & Treatment & Bolting date & $\begin{array}{c}\text { Percentage of } \\
\text { bolting }(\%)\end{array}$ & Flowering date & $\begin{array}{l}\text { Percentage of } \\
\text { flowering }(\%)\end{array}$ \\
\hline \multirow[t]{4}{*}{ 'Bolero White' } & $0 \mathrm{D}$ & 19-Sep bz & $100 \mathrm{a}^{\mathrm{y}}$ & 23-Nov b & $100 \mathrm{a}$ \\
\hline & $3 \mathrm{D} / 3 \mathrm{D}$ & 14-Sep a & $100 \mathrm{a}$ & 12-Nov a & $100 \mathrm{a}$ \\
\hline & $6 \mathrm{D} / 6 \mathrm{D}$ & 15-Sep a & $100 \mathrm{a}$ & 14-Nov a & $100 \mathrm{a}$ \\
\hline & $15 \mathrm{D} / 15 \mathrm{D}$ & 19-Sep b & $100 \mathrm{a}$ & 23-Nov b & $100 \mathrm{a}$ \\
\hline \multirow[t]{4}{*}{ 'Nancy' } & $0 \mathrm{D}$ & 28-Sep b & $100 \mathrm{a}$ & 7-Dec b & $66.7 \mathrm{~b}$ \\
\hline & $3 \mathrm{D} / 3 \mathrm{D}$ & 17-Sep a & $100 \mathrm{a}$ & 16-Nov a & $100 \mathrm{a}$ \\
\hline & $6 \mathrm{D} / 6 \mathrm{D}$ & 17-Sep a & $100 \mathrm{a}$ & 17-Nov a & $100 \mathrm{a}$ \\
\hline & $15 \mathrm{D} / 15 \mathrm{D}$ & 22-Sep ab & $100 \mathrm{a}$ & $30-$ Nov b & $100 \mathrm{a}$ \\
\hline
\end{tabular}

${ }^{z}$ Mean values $(\mathrm{n}=3)$ followed by different letters indicate significant differences among different cycles of ILTS $(P<0.05$, Tukey's HSD test).

y Percentage values were transformed to arcsin values.

Table 4. Effects of ILTS cycles on the harvesting date, percentage of harvesting, and cut flower characteristics of 'Nancy' up to December 31 in 2013. Details of treatments are presented in Figure 1.

\begin{tabular}{ccccccc}
\hline \hline Treatment & Harvesting date & $\begin{array}{c}\text { Percentage of } \\
\text { harvesting (\%) }\end{array}$ & $\begin{array}{c}\text { Cut flower } \\
\text { length }(\mathrm{cm})\end{array}$ & $\begin{array}{c}\text { Cut flower } \\
\text { weight (g) }\end{array}$ & $\begin{array}{c}\text { Number of nodes } \\
\text { to the first flower }\end{array}$ & $\begin{array}{c}\text { Percentage of } \\
\text { marketable } \\
\text { harvesting (\%) }\end{array}$ \\
\hline 0D & 25-Dec b & $62.5 \mathrm{~b}^{\mathrm{y}}$ & $46.1 \mathrm{a}$ & $36.8 \mathrm{a}$ & $11.0 \mathrm{~b}$ & $62.5 \mathrm{a}$ \\
3D/3D & 29-Nov a & $100.0 \mathrm{a}$ & $65.1 \mathrm{a}$ & $41.4 \mathrm{a}$ & $10.5 \mathrm{ab}$ & $94.1 \mathrm{a}$ \\
6D/6D & 3-Dec a & $100.0 \mathrm{a}$ & $71.9 \mathrm{a}$ & $56.4 \mathrm{a}$ & $10.2 \mathrm{a}$ & $100.0 \mathrm{a}$ \\
15D/15D & 17-Dec b & $100.0 \mathrm{a}$ & $73.3 \mathrm{a}$ & $54.4 \mathrm{a}$ & $10.9 \mathrm{~b}$ & $83.3 \mathrm{a}$ \\
\hline
\end{tabular}

${ }^{z}$ Mean values $(\mathrm{n}=3)$ followed by different letters indicate significant differences among different cycles of ILTS $(P<0.05$, Tukey's HSD test).

y Percentage values were transformed to arcsin values.

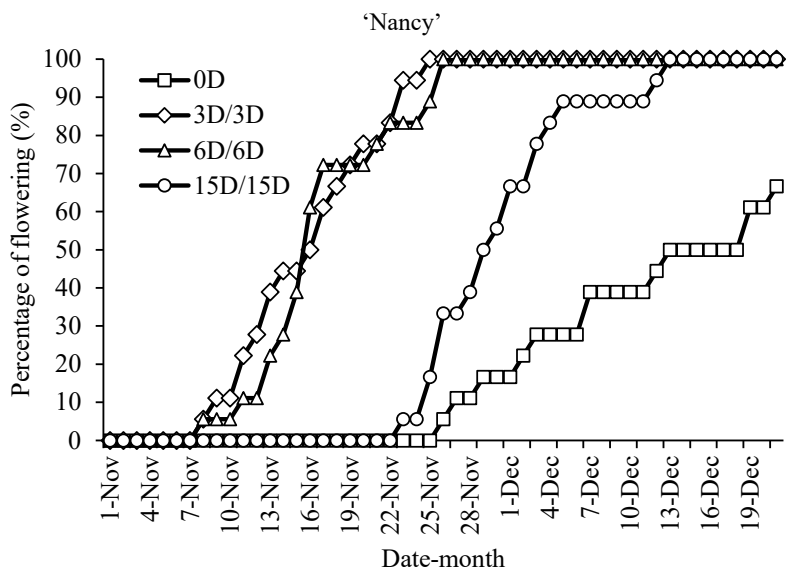

Fig. 6. Percentage of flowering of 'Nancy' recorded in different cycles of ILTS every day until December 21.

significant difference in the fresh weight or length of cut flowers among treatments. The number of nodes to the first flower in ILTS cycles of $6 \mathrm{D} / 6 \mathrm{D}$ was smaller than that in the $15 \mathrm{D} / 15 \mathrm{D}$ cycle in 'Nancy'. There was no significant difference in these values among treatments in 'Bolero White' (data not shown).

\section{Discussion}

To produce Eustoma cut flowers for the New Year holidays in the warm southwestern area in Japan, it is necessary to successfully grow seedlings in the summer. Cold imbibition of the seeds of Eustoma can prevent rosetting, but does not induce flowering sufficiently and cut flower harvesting may be limited up to the end of the year if the greenhouse temperature is not actively cooled while raising the seedlings in the summer. Accordingly, in this study, we investigated whether flowering, cut flower harvesting, and cut flower quality could be improved using intermittent low temperature storage (ILTS) in several cultivars with different susceptibilities to rosetting, all of which had their seeds pre-treated with cold imbibition.

In the experimental design, the total number of cold storage days and the lengths of ILTS cycles were determined as follows. In traditional commercial cultivation, Eustoma rosetted seedlings are placed in a refrigerator at $10^{\circ} \mathrm{C}$ for $30-35$ days to break rosetting (Ninomiya et al., 1997). During this time, irrigation is performed once a week. In the ILTS procedure, irrigation is not applied while the seedlings are stored at low temperatures under a dark condition. Therefore, in Experiment 1, we decided to store seedlings at low temperatures intermittently every six days, up to 30 days.

As the minimum temperature during the seedling stage was over $25^{\circ} \mathrm{C}$ (Fig. 5), plant growth and flowering suppression were likely to occur. Seedlings not stored at low temperatures (control) rarely bolted in 'Exe Lavender' and 'Nancy' because young Eustoma 
seedlings, especially just after germination, are very sensitive to high temperatures and rosetting is easily induced (Harbaugh et al., 1992; Ohkawa et al., 1991). Most seedlings bolted when seeds were subjected to $10^{\circ} \mathrm{C}$ imbibition for 35 days before sowing. However, it was found that only half of the plants grown from coldimbibed seeds without ILTS treatment flowered up to December 20. Similarly, the effect of high temperature on reducing bolting can be avoided by other low temperature treatments such as artificial night cooling, low ambient temperatures, or planting in highlands; however, flowering was not induced in all plants that bolted (Ohkawa et al., 1996). Therefore, we confirmed that applying only cold imbibition to Eustoma seeds was insufficient to stimulate flowering after stem elongation when growing them at high ambient temperatures.

The total number of cold storage days depended on the number of cycles of $6 \mathrm{D} / 6 \mathrm{D}$ in ILTS. The seedlings treated with ILTS after cold imbibition of the seeds resulted in early bolting and flowering and a higher percentage of flowering in both 'Exe Lavender' and 'Nancy'. Nevertheless, it was found that flowering was affected by the duration of low temperature storage applied intermittently after the cold imbibition of the seeds; a longer duration of low temperature exposure (more than 18 days) increased the percentage of flowering. The induced flowering was maximum $(100 \%)$ in both 24 and 30 DCS. In both 'Exe Lavender' and 'Nancy', the first flower buds of 24 and 30 DCS opened earlier than those of 6, 12, and 18 DCS (Figs. 3 and 4). Thus, length of low temperature storage has a great impact on bolting and flowering timing of Eustoma.

When the high-rosetting cultivar 'Nancy' was exposed to low temperatures for 30 days, the percentage of cut flowers reached $100 \%$ before December 31 and the longest fresh cut flower was achieved (Table 2). The percentage of flowering was significantly lower in 6 , 12 , and 18 DCS than 30 DCS. Thus, it is possible that the effect of low temperature exposure after sowing can be mitigated by the duration of high ambient temperature exposure. A similar result was found in a previous study where a shortened duration of cold imbibition (from five weeks to one week) reduced the bolting rate of Eustoma sown under a high ambient temperature (Tanigawa et al., 2002). In order to control the flowering effectively, as well as harvesting high-rosetting Eustoma cultivars, cold exposure with ILTS should be 24 days or longer. This will enable growers to produce Eustoma cut flowers in the winter without applying air conditioning to the entire greenhouse in the summer; therefore, applying ILTS can be considered as a lowcost method.

Furthermore, we examined the lengths of ILTS cycles when the total number of cold storage days was 30 days. No significant difference was observed between $3 \mathrm{D} / 3 \mathrm{D}$ and $6 \mathrm{D} / 6 \mathrm{D}$ in bolting and flowering. In this experiment, the percentages of flowering and harvesting were $100 \%$ in all the plants treated with ILTS. If the total low temperature duration of ILTS is the same, there may be no difference in the effects when the treatment cycle is changed between three days to six days. As such, it is interesting that the effectiveness of continuous low temperature exposure on Eustoma seedlings could be divided into brief durations while the total amount of low temperature exposure was the same. This finding was consistent with the report of Nakajima and Goto (2018) who reported that the day of blooming after ILTS cycles of $2 \mathrm{D} / 2 \mathrm{D} \times 8$ times was similar to that of cycles of $4 \mathrm{D} / 4 \mathrm{D} \times 4$ times in Begonia $\times$ hiemalis 'Netja'. Continuous low temperature exposure was also effective in inducing flowering in rosetting cultivars of Eustoma after transplanting at four weeks (Ohkawa et al., 1994; Pergola, 1992); however, no report has examined the potential of applying interrupted low temperature storage for growing seedlings. This is the first report to show that bolting and flowering of Eustoma can be achieved successfully under constant interruption of low temperature exposure.

Even though the duration of low temperature storage was applied for the same 30 DCS, the cycle of 15D/15D was less effective for Eustoma compared to cycles of $3 \mathrm{D} / 3 \mathrm{D}$ and $6 \mathrm{D} / 6 \mathrm{D}$. Seedlings grown under ILTS with $15 \mathrm{D} / 15 \mathrm{D}$ showed significantly later bolting, flowering, and harvesting than with cycles of $3 \mathrm{D} / 3 \mathrm{D}$ and $6 \mathrm{D} / 6 \mathrm{D}$, and there was a lower percentage of marketable harvest in 'Nancy'. The starting time of low temperature exposure for seedlings was too late in $15 \mathrm{D} / 15 \mathrm{D}$ and 15 days of ambient high temperature may have negatively affected development (Fig. 1). Murata et al. (1990) reported that flowering of Eustoma was delayed when night air cooling was applied two weeks after sowing compared to that applied immediately after sowing. In another report, the percentage of flowering in Eustoma 'GCREC-Blue' decreased when the young seedlings were exposed to high temperature (Harbaugh, 1995). These results suggest that the low temperature effect obtained during seed cold-imbibition may be reduced by high temperature exposure immediately after sowing. The start time of ILTS in the cycle of $15 \mathrm{D} / 15 \mathrm{D}$ should be investigated to see if it affects the bolting and flowering ability of Eustoma.

This report suggests that the negative effects of high ambient temperatures can be reduced by applying ILTS after sowing of cold-imbibed seeds instead of using air conditioners to cool down the temperatures of greenhouses. The duration of low temperature exposure should be 24 days or longer using 6D/6D of ILTS at $10^{\circ} \mathrm{C}$ to improve the flowering rate and cut flower yield at the end of the year.

\section{Literature Cited}

Fukushima, K., S. Kajihara, S. Ishikura, N. Katsutani and T. Goto. 2017. Effect of exposing imbibed seeds to low temperatures on the growth and characteristics of Eustoma 
grandiflorum. Hort. Res. (Japan) 16: 177-184 (In Japanese with English abstract).

Harbaugh, B. K. 1995. Flowering of Eustoma grandiflorum (Raf.) Shinn. cultivars influenced by photoperiod and temperature. HortScience 30: 1375-1377.

Harbaugh, B. K., M. S. Roh, R. H. Lawson and B. Pemberton. 1992. Rosetting of lisianthus cultivars exposed to high temperature. HortScience 27: 885-887.

Kageyama, Y., Y. Fukushima and K. Konishi. 1990. Effects of raising seedling at cool temperature and chilling treatment of seed on rosette formation of Eustoma. J. Japan. Soc. Hort. Sci. 59 (Suppl. 1): 496-497 (In Japanese).

Li, J., Y. Notsu, I. M. Ogawa, H. Ohno and K. Ohkawa. 2002. Rosetting characteristics-based classification of Eustoma grandiflorum (Raf.) Shinn. cultivars sown on different dates. Environ. Control Biol. 40: 229-237.

Murata, T., Y. Iwakiri and H. Takahashi. 1990. Effects of cooling treatment in night with seedling of Eustoma russellianum on growth and flowering. Kyushu Agricultural Research 53: 202 (In Japanese).

Nakajima, T. and T. Goto. 2018. Effect of intermittent low temperature storage on flowering and growth acceleration of Begonia $\times$ hiemalis 'Netja.' Hort. Res. (Japan) 17: 73-78 (In Japanese with English abstract).

Ninomiya, C., K. Takano and A. Azuma. 1997. Effect of duration of the temperature treatment on growth and development in greenhouse controled at low night temperature after planting. Bull. Kochi Agric. Res. Cent. 6: 31-36 (In Japanese with English abstract).
Ohkawa, K., A. Kano, K. Kanematsu and M. Korenaga. 1991. Effects of air temperature and time on rosette formation in seedlings of Eustoma grandiflorum. Sci. Agric. 48: 171176.

Ohkawa, K., S. Yamaguchi, M. Miyoshi and A. Yamazaki. 1996. Forcing of rosetted Eustoma grandifforum seedlings by low temperature treatments. Environ. Control Biol. 34: 45-52.

Ohkawa, K., T. Yoshizumi, M. Korenaga and K. Kanematsu. 1994. Reversal of heat-induced rosetting in Eustoma grandiflorum with low temperatures. HortScience 29: 165166.

Pergola, G. 1992. The need for vernalization in Eustoma russellianum. Sci. Hortic. 51: 123-127.

Takeda, T. 1995. Effects of low temperature treatments on bolting and flowering of rosetted Eustoma Seedlings. J. Japan. Soc. Hort. Sci. 64: 356-366 (In Japanese with English abstract).

Tanigawa, T., Y. Kobayashi and T. Kunitake. 1999. Low temperature treatment of imbibed seeds and varietal differences in the rate of bolting and flowering under high-temperature condition in Eustoma grandiflorum. J. Japan. Soc. Hortic. Sci. 68 (Suppl. 2): 378 (In Japanese).

Tanigawa, T., N. Kuroyanagi and T. Kunitake. 2002. Effects of low temperature treatment of imbibed seeds of Eustoma grandiflorum (Raf.) Shinn. on their germination and subsequent bolting. J. Japan. Soc. Hort. Sci. 71: 697-701 (In Japanese with English abstract).

Yoshida, Y., E. Ozaki, K. Murakami and T. Goto. 2012. Flower induction in June-bearing strawberry by intermittent low temperature storage. J. Japan. Soc. Hort. Sci. 81: 343-349. 